\title{
Estimation of yearly, monthly and weekly drought for Aurangabad district of Maharashtra
}

\section{S.H. JEDHE, S.B. JADHAV AND V.P. MANDALE}

Article Chronicle :

Received :

09.07.2014;

Accepted :

22.11.2014
SUMMARY : The rainfall distribution of Aurangabad district of Maharashtra state is quite erratic in space and occurrence of drought is common. In this study 21 years (1991-2011) of rainfall data of Aurangabad district have been analyzed on yearly, monthly and weekly basis for predicting the water drought, normal and surplus events for crop planning in the region. Weekly drought normal and surplus events give a more precise idea about crop planning than yearly and monthly events. The analysis has revealed that the percentage of drought weeks was more than normal and surplus weeks. It has been also revealed that there is a need of assured supplemental irrigation facility in Rabi and summer season crops.

HOW TO CITE THIS ARTICLE : Jedhe, S.H., Jadhav, S.B. and Mandale, V.P. (2014). Estimation of yearly, monthly and weekly drought for Aurangabad district of Maharashtra. Asian J. Environ. Sci., 9(2): 87-90.

Key Words :

Crop planning,

Drought,

Supplemental

irrigation

Author for correspondence :

\section{S.H. JEDHE}

TMC, Vasantrao Naik

Marathwada Krishi

Vidyapeeth, PARBHANI

(M.S.) INDIA

Email: jedhesh07@gmail.

com

See end of the article for

Coopted authors' 